\title{
Effects of Different Heel Heights on Plantar Foot Pressure Distribution of Older Women during Walking
}

\author{
Jin-Seop Kim, PT, PhD ${ }^{1)}$, Dennis W. Fell, PT, MD²), Yong Jun Cha, PT, PhD ${ }^{3)}$, \\ JAe Eung You, PT, PhD ${ }^{4}$, Kyoung KIM, PT, $\mathrm{PhD}^{1)}$ \\ 1) Department of Physical Therapy, Daegu University: 15 Naeri-ri, Jinlyang, Gyeongsan-si, \\ Kyeongsangbuk-do, Republic of Korea. TEL: +82 53-850-4351, FAX: +82 53-850-4351, E-mail: \\ kykim257@hanmail.net \\ 2) Department of Physical Therapy, University of South Alabama \\ 3) Department of Physical Therapy, Daejeon University \\ 4) Department of Tour and Recreation, Korea Tourism College
}

\begin{abstract}
Purpose] This study was performed to investigate changes in plantar foot pressure distribution of older women during walking in shoes with different heel heights. [Subjects] Fourteen older women without foot problems participated in the study. [Methods] Heel heights of the shoes were standardized as $1 \mathrm{~cm}, 3 \mathrm{~cm}$, and $5 \mathrm{~cm}$. Plantar foot pressure was recorded using the F-scan system (Tekscan Inc, Boston, USA). One-way repeated ANOVA was used to compare foot data obtained at the different heel heights. [Results] Peak plantar pressure values of the dominant lower limb showed significant differences among the different heel heights during the stance phase of gait at the T2-5, M2, MF, and $\mathrm{H}$ regions. The contact area of the dominant limb showed significant differences among the different heights at the T2-5, M1, M2, M3, MF, H regions. Antero-posterior and medio-lateral displacements of the trajectory of center of pressure (TCOP) were significantly different among the different heel heights. [Conclusion] Foot pressure distributions of the older women indicate gait pattern altered with shoe heel height. Key words: Plantar foot pressure, Heel heights, Older women
\end{abstract}

(This article was submitted May 1, 2012, and was accepted Jun. 13, 2012)

\section{INTRODUCTION}

Women wear shoes with different heel heights and many women prefer to wear high-heeled shoes on a daily basis ${ }^{1)}$. Older women who wear high-heeled shoes have an $83 \%$ prevalence of foot problems and usually have more foot problems than younger women ${ }^{2}$. The main problems associated with high-heeled shoes are that they reduce balance and increase the risk of falling ${ }^{3,4)}$. However, older women sometimes wear high-heeled shoes during work and daily life ${ }^{5)}$.

Older women have difficulty walking while wearing high-heeled shoes and this contributes to an increased fall rate $^{6}$. In addition, heel height and heel width influence gait, posture, and the tendency to tip sideways on uneven surfaces ${ }^{7)}$. Walking while wearing high-heeled shoes affects gait and posture, and requires specific coordinated contractions of the lower limbs and trunk muscles ${ }^{8)}$. Static and dynamic pressures on the foot can be quantified by measuring plantar foot pressure. Furthermore, the pressures exerted on various regions can be observed during different motions and functional activities. Through such observations, influences on individual foot regions can be accurately assessed and analyzed to provide information for the diagnosis and treatment of injuries or to monitor the progress of treatment ${ }^{9}$. Foot pressure studies of older people during walking have focused on changes in plantar foot pressure in relation to age ${ }^{10,11)}$. They have found that older women generally have an increase in forefoot and heel peak pressure while walking as heel height increases. Therefore, the purpose of this study was to determine peak plantar pressure and contact area patterns of the dominant lower limb of older women at different heel heights while walking, in order to provide basic data for the design of safer and more efficient heels, and to recommend shoes for older women. The study tested the hypothesis that heel height increase would change peak plantar pressure, contact area, and trajectory COP during walking.

\section{SUBJECTS AND METHODS}

Fourteen healthy older women volunteered for this study. A description of the purpose and method was provided to each participant and the trials were conducted after participants had read and signed an informed consent form. The study inclusion criteria were a Frenchay Instrumental Activities of Daily Living score ${ }^{12)}$ of $>36$, a Physical Function score $^{13)}$ of $>20$, and a Berg Functional Balance Scale score ${ }^{14)}$ of $>44$. All participants scored greater than 24 on the Mini Mental Status Examination (MMSE) ${ }^{15}$. By self-report, all 
Table 1. Subject characteristics

\begin{tabular}{lllcl}
\hline $\begin{array}{l}\text { Age } \\
\text { (years })\end{array}$ & $\begin{array}{l}\text { Weight } \\
(\mathrm{kg})\end{array}$ & $\begin{array}{l}\text { Height } \\
(\mathrm{cm})\end{array}$ & $\begin{array}{l}\text { Shoes size } \\
(\mathrm{mm})\end{array}$ & $\begin{array}{l}\text { Dominant side } \\
(\mathrm{R} / \mathrm{L})\end{array}$ \\
\hline $71.7 \pm 4.4$ & $47.5 \pm 3.1$ & $149.5 \pm 3.5$ & $241.4 \pm 4.1$ & $12 / 2$ \\
\hline
\end{tabular}

$(\mathrm{N}=14)$ Values are expressed as mean \pm standard deviation

participants reported having one or more falls in the previous year. Exclusion criteria were severe dementia (an MMSE score $<20$ ) and the inability to walk independently. Subject characteristics are summarized in Table 1.

The F-scan in-shoe system (Tekscan Inc, USA) with a 10-m walkway was used to measure plantar foot pressures during the stance phase while walking in shoes with different heel heights. The F-scan in-shoe system consists of a pressure sensitive insole which contains $0.15 \mathrm{~mm}$ thick sensors embedded in grid of 960 pressure-sensing cells, evenly distributed at $0.5 \mathrm{~cm}$ (0.2 in) intervals. Before use, the disposable insole was trimmed to fit into the individual shoes. A $9.25 \mathrm{~m}$ cable was connected to the sensor and the sensor was set to sample data at $50 \mathrm{~Hz}$ for 4 seconds.

The shoes used in this study were commercially available items, and they were selected for similarity of construction including foot contact points, supports and pump style. The main difference among these shoes was the height of the heel: a flat $(1.0 \mathrm{~cm})$, a low $(3.0 \mathrm{~cm})$ and a high heel $(5.1 \mathrm{~cm})$. Each participant walked on a treadmill for $5 \mathrm{~min}$ at $1.3 \mathrm{mph}$ to become familiar with each heel height and walking speed. After familiarization, the insole was put in each shoe, and the subjects walked approximately 20 to 30 meters over ground to acquaint themselves with the system. Wearing each pair of shoes, the subjects performed 3 walks of at least 3 strides over ground. To prevent fatigue, each participant took a 3-min rest between each trial. Plantar pressure was recorded for three strides in the middle of the test walk on the dominant side only, and mean pressure values were calculated for the dominant side. Recorded pressure data was processed using commercial software, F-scan version 4.19F.

The plantar area was divided into 7 regions: T1, Hallux; T2-5, Toe 2-5; M1, Metatarsal 1; M2, Metatarsal 2-3; M3, Metatarsal 4-5; MF, Mid-foot; H, Heel. Average peak pressure and contact area of the dominant side were calculated for each foot region. One-way repeated measures ANOVA was used to analyze peak plantar pressures and contact area of each foot region among the different heel heights using 0.05 as the alpha level for significance.

\section{RESULTS}

Table 2 shows peak plantar pressure values of the plantar regions of the dominant lower limb at the different heel heights during walking. In the T1, M1, and M3 metatarsal regions, no significant differences were observed among the heel heights. In the T2-5 regions, compared to the other heel heights, significantly increased peak plantar pressure values was observed at a heel height of $5 \mathrm{~cm}$. In the M2 metatarsal region, compared to the $3 \mathrm{~cm}$ heels, high peak plantar pressure values were observed for the $1 \mathrm{~cm}$ heels while walking, but a decrease was observed for the $5 \mathrm{~cm}$ heels. In the MF region, compared to the $1 \mathrm{~cm}$ heels, peak plantar pressure was significantly higher for the $3 \mathrm{~cm}$ heels while walking but was significantly lower for the $5 \mathrm{~cm}$ heels. The $\mathrm{H}$ region, compared to the $1 \mathrm{~cm}$ heels, showed an increase in peak plantar pressure for the $5 \mathrm{~cm}$ heels, but a decrease for $3 \mathrm{~cm}$ heels.

Table 3 shows contact area values of the dominant limb at the different heel heights during walking. In the T2-T5 toe regions, the contact area was significantly higher for the $1 \mathrm{~cm}$ heels compared to the other heel heights. In the M1 region, compared to the $1 \mathrm{~cm}$ heels, the contact area was significantly higher for the $3 \mathrm{~cm}$ heels, but significantly lower for the $5 \mathrm{~cm}$ heels. In the M2 region, the contact area was significantly increased for the $1 \mathrm{~cm}$ heels compared to the other heel heights. Based on the results of post hoc tests, the differences in walking between $1 \mathrm{~cm}$ and $3 \mathrm{~cm}$ heels and between $1 \mathrm{~cm}$ and $5 \mathrm{~cm}$ heels were significant. In the M3 region, the contact area was higher for the $1 \mathrm{~cm}$ heels than the other heel heights. In the MF region, compared to the $1 \mathrm{~cm}$ heels, the contact area was higher for the $3 \mathrm{~cm}$ heels, but lower for the $5 \mathrm{~cm}$ heels. The contact area of the $\mathrm{H}$ region significantly increased for the $5 \mathrm{~cm}$ heels compared to the other heel heights.

Table 4 shows antero-posterior (AP) and medio-lateral (ML) displacements of trajectory center of pressure (TCOP). AP displacement of TCOP decreased significantly with increased heel height. In addition, ML displacement of TCOP was significantly less for the $3 \mathrm{~cm}$ heels than for the $1 \mathrm{~cm}$ or $5 \mathrm{~cm}$ heels.

\section{DISCUSSION}

Fall rates are known to increase with age ${ }^{16)}$, and women are more likely to fall than men ${ }^{17)}$. The results of this study support our hypothesis that heel height increase would change peak plantar pressure, contact area, and trajectory COP during walking which could further influence fall risk, and has implications for education and recommendations for shoes that elderly women should wear.

Peak plantar pressure refers to peak pressure by region when the plantar surface contacts the ground. In a previous study, as heel height increased in healthy young women of 22 years old, peak plantar pressure increased in the fore-foot and heel regions with small changes in the mid-foot region $^{17)}$. In the present study, the peak plantar pressures of the dominant lower limb during the stance phase increased in the T2-5 region and heel region when $5 \mathrm{~cm}$ heels were worn, and were considerably lower when $3-\mathrm{cm}$ heels were worn. This result is consistent with a previous study on the 
Table 2. Peak plantar foot pressure distribution of the dominant lower limb during walking with different heel heights

\begin{tabular}{lccc}
\hline Region & $1 \mathrm{~cm}$ heel & $3 \mathrm{~cm}$ heel & $5 \mathrm{~cm}$ heel \\
\hline T1 & $238.1 \pm 102.8$ & $223.1 \pm 93.5$ & $182.7 \pm 94.7$ \\
T2-5 & $159.8 \pm 62.0$ & $126.4 \pm 52.9$ & $162.2^{*} \pm 112.2$ \\
M1 & $216.0 \pm 69.7$ & $234.4 \pm 76.8$ & $263.9 \pm 12$ \\
M2 & $205.2 * \pm 55.2$ & $152.1 \pm 19.1$ & $129.6 \pm 21.2$ \\
M3 & $170.4 \pm 135.6$ & $104.0 \pm 24.5$ & $101.5 \pm 30.1$ \\
MF & $95.2 \pm 30.4$ & $159.2 * \pm 81.7$ & $57.0 \pm 22.4$ \\
H & $193.4 \pm 33.7$ & $162.7 \pm 28.2$ & $220.8^{*} \pm 53.3$ \\
\hline
\end{tabular}

(Unit:Kpa) Values are expressed as mean \pm standard deviation. T1: Hallux, T2-5: Toe 2-5, M1: Metatarsal 1, M2: Metatarsal 2-3, M3: Metatarsal 4-5, MF: Mid-foot, H: Heel. * $\mathrm{p}<0.05$.

distribution of peak plantar pressures of healthy women wearing different heel heights, indicating that older women wearing $5 \mathrm{~cm}$ heels are very dependent on the T2-5 and heel regions for weight-bearing.

In a previous study, contact area showed decreased loading on the mid-foot and heel of healthy women wearing high heels ${ }^{17)}$. In addition, Hessert et al. ${ }^{10)}$ reported that forces and pressures under the medial foot decrease for elderly people. In the present study, the contact area of the dominant lower limb during the stance phase showed significant decreases compared to the other heel heights at M1, M2, M3, and MF in the medial foot region when $5 \mathrm{~cm}$ heels were worn, but contact area of the heel region of older women wearing $5 \mathrm{~cm}$ heels increased. Our results for the contact areas in the medial region are consistent with the reports of Speksnijder et al. ${ }^{17)}$ and Hessert et al. ${ }^{10)}$ However, the results for pressure of the heel region might be related to common walking patterns of older subjects, including slower velocity with a shorter step length, which may result in increased weight bearing on the heel region at slower walking speeds.

In previous studies, regular wearers of high-heel shoes reported a feeling of lack of foot stability after heel strike ${ }^{18)}$ and $\mathrm{Kim}^{19)}$ concluded that older adults reduce their AP and ML displacement of COP during obstacle-crossing. In the present study, AP displacement of TCOP was significantly reduced by increased heel height, and ML displacement of TCOP displacement significantly decreased at the $3 \mathrm{~cm}$ heel height, as compared with $1 \mathrm{~cm}$ and $5 \mathrm{~cm}$ heel heights during walking. Perhaps, AP displacement of TCOP when wearing the 1 or $3 \mathrm{~cm}$ heels reflects better mobility than when wearing the $5 \mathrm{~cm}$ heels. Furthermore, the lower ML displacement of TCOP when wearing $3 \mathrm{~cm}$ heels may indicate better stability than 1 or $5 \mathrm{~cm}$ heels, possibly because all heels are inherently less stable as the center of mass moves further from the support surface or there are changes in the joint surface at the $1 \mathrm{~cm}$ heel height that make the ankle less stable.

In conclusion, the results of the present study indicate gait was more stable and more likely to prevent fall events when older women wore 1 or $3 \mathrm{~cm}$ heels. In addition, low heel heights would likely decrease the imbalance seen in gait and this study provides valuable information regarding the selection of shoes for older women. This study adds to
Table 3. Plantar foot contact area distribution of the dominant lower limb during walking with different heel heights

\begin{tabular}{lccc}
\hline Region & $1 \mathrm{~cm}$ heel & $3 \mathrm{~cm}$ heel & $5 \mathrm{~cm}$ heel \\
\hline T1 & $8.6 \pm 1.3$ & $8.7 \pm 1.6$ & $8.6 \pm 1.3$ \\
T2-5 & $5.5^{*} \pm 1.8$ & $3.5 \pm 1.4$ & $4.4 \pm 2.1$ \\
M1 & $21.3 \pm 2.8$ & $26.1^{*} \pm 3.2$ & $20.9 \pm 2.5$ \\
M2 & $13.2^{*} \pm 0.2$ & $12.7 \pm 0.4$ & $11.4 \pm 1.2$ \\
M3 & $10.1^{*} \pm 1.7$ & $5.8 \pm 2.2$ & $6.0 \pm 2.1$ \\
MF & $18.0 \pm 6.2$ & $20.4^{*} \pm 2.8$ & $16.9 \pm 5.2$ \\
H & $30.7 \pm 2.4$ & $36.5 \pm 1.6$ & $39.0^{*} \pm 6.6$ \\
\hline
\end{tabular}

(Unit: $\mathrm{cm}^{2}$ ) Values are expressed as mean \pm standard deviation. T1: Hallux, T2-5: Toe 2-5, M1: Metatarsal 1, M2: Metatarsal 2-3, M3: Metatarsal 4-5, MF: Mid-foot, H: Heel. * ${ }^{*}<0.05$.

Table 4. Anteroposterior and mediolateral displacements of the dominant foot trajectory of central of pressure (TCOP) for shoes of different heel heights

\begin{tabular}{crcc}
\hline & $1 \mathrm{~cm}$ heel & $3 \mathrm{~cm}$ heel & $5 \mathrm{~cm}$ heel \\
\hline AP displacement & $32.2 \pm 3.3$ & $29.6 \pm 2.0$ & $26.1^{*} \pm 3.6$ \\
ML displacement & $2.1 \pm 0.5$ & $1.6^{*} \pm 0.3$ & $2.2 \pm 0.8$ \\
\hline
\end{tabular}

(Unit: $\mathrm{cm}$ ) Values are expressed as mean \pm standard deviation. $* \mathrm{p}<0.05$.

the building evidence that there are differences in balance, forward propulsion, and pressure distribution between the elderly and young women.

Limitations of this study include a small sample size, and the lack of specific measurement of subject's ankle and knee ROM for analysis. Moreover, participants did not wear their own shoes (to standardize heel height) to enable precise correlation of heel height with plantar pressure distribution. Future studies should employ larger sample sizes, and include examination of variations of foot and knee ROM related to the plantar pressures of different heel heights of healthy elderly women during walking.

\section{REFERENCES}

1) Frey C, Thompson F, Smith J, et al.: American orthopaedic foot and ankle society women's shoe survey. Foot Ankle, 1993, 14: 78-81. [Medline]

2) Dawson J, Torogood M, Marks SA, et al.: The prevalence of foot problems in older women: a cause for concern. J Public Health Med, 2002, 24: 77-84. [Medline] [CrossRef]

3) Menz HB, Lord SR: Footwear and postural stability in older people. J Am Podiatr Med Assoc, 1999, 89: 346-357. [Medline]

4) Menz HB, Morris ME, Lord SR, et al.: Footwear characteristics and risk of indoor and outdoor falls in older people. Gerontology, 2006, 52: 174-180. [Medline] [CrossRef]

5) Menant JC, Steele JR, Menz HB, et al.: Effects of walking surfaces and footwear on temporo-spatial gait parameters in young and older people. Gait Posture, 2009, 29: 392-397. [Medline] [CrossRef]

6) Lord SR, Bashford GM: Shoe characteristics and balance in older women. J Am Geriatr Soc, 1996, 44: 429-433. [Medline]

7) Brecht JS, Chang MW, Price R, et al.: Decreased balance performance in cowboy boots compared with tennis shoes. Arch Phys Med Rehabil, 1995, 76: 940-946. [Medline] [CrossRef]

8) Lindemann U, Scheible S, Sturm E, et al.: Elevated heels and adaptation to new shoes in frail elderly women. Z Gerontol Geriatr, 2003, 36: 29-34. [Medline] [CrossRef] 
9) Chevalier TL, Hodgins H, Chockalingam N, et al.: Plantar pressure measurements using an in-shoe system and a pressure platform: A comparison. Gait Posture, 2010, 31: 397-399. [Medline] [CrossRef]

10) Koehler M, Rabinowitz T, Hirdes J, et al.: Foot pressure distribution during walking in young and old adults. BMC Geriatr, 2005, 5: 1-8. [Medline] [CrossRef]

11) Yung-Hui L, Wei-Hsien H: Effects of shoe inserts and heel height on foot pressure, impact force, and perceived comfort during walking. Appl Ergon, 2005, 36: 355-362. [Medline] [CrossRef]

12) Schuling J, de Haan R, Limburg M, et al.: The frenchay activities index Assessment of functional status in stroke patients. Stroke, 1993, 24 1173-1177. [Medline] [CrossRef]

13) Ware JE Jr, Sherbourne CD: The MOS 36-item short-form healthy survey (SF-36). I. Conceptual framework and item selection. Med Care, 1992, 30: 473-483. [Medline] [CrossRef]
14) Berg KO, Wood-Dauphinee SL, Williams JI, et al.: Measuring balance in the elderly: preliminary development of an instrument. Physiother Can, 1989, 41: 304-311. [CrossRef]

15) Tombaugh TN, Mclntyre NJ: The mini-mental state examination: a comprehensive review. J Am Geriatr Soc, 1992, 40: 922-935. [Medline]

16) Menz HB, Morris ME: Clinical determinants of plantar forces and pressures during walking in older people. Gait Posture, 2006, 24: 229-236. [Medline] [CrossRef]

17) Speksnijder CM, Munckhof Rieny JH, Moonen Sjors AF, et al.: The higher the heel the higher the forefoot-pressure in ten healthy women. Foot, 2005, 15: 17-21. [CrossRef]

18) Lee CM, Jeong EH, Freivalds A: Biomechanical effects of wearing highheeled shoes. Inter J Indus Ergo, 2001, 28: 321-326. [CrossRef]

19) Kim HD: Age-related changes in the center of pressure trajectory during obstacle crossing. J Phys Ther Sci, 2009, 21: 75-80. [CrossRef] 